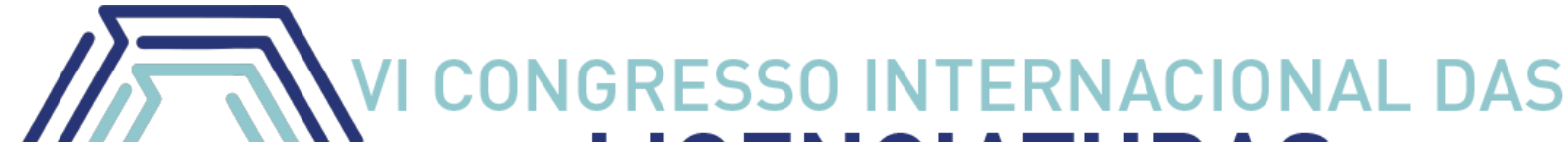 LICENCIATURAS COINTER - PDVL 2019
}

\section{A IMPORTÂNCIA DA EAD PARA PROFESSORES DA REDE PÚBLICA MUNICIPAL DO MUNICÍPIO DE ARAGUATINS-TO}

\section{LA IMPORTANCIA DE EAD PARA LOS PROFESORES DE RED PUBLICA DISTRITO MUNICIPAL DE ARAGUATINS - A}

\section{THEIMPORTANCEOF EAD FORPUBLICNETWORK TEACHERS MUNICIPALDISTRICTOF ARAGUATINS - TO}

\author{
Apresentação: Comunicação Oral \\ Kelly Luana de Sousa Silva ${ }^{1}$; Tiago Azevedo da Silva ${ }^{2}$; Ramasio Ferreira de Melo ${ }^{3}$
}

DOI: $\underline{\text { https://doi.org/10.31692/2358-9728.VICOINTERPDVL.2019.0116 }}$

\section{Resumo}

A formação e especialização a distância de professores vem se tornando cada vez mais frequente e na rede pública de todo o país não é diferente, em função disso foi realizada uma pesquisa nas instituições municipais de ensino da cidade de Araguatins - TO para analisar de que forma a educação a distância influenciou na formação acadêmica dos professores dessas escolas, devido a esse crescimento é necessário uma avaliação do desempenho e dificuldades encontrados por esses profissionais durante sua formação e pratica, e requer uma maior atenção por parte do governo e das escolas, pois mesmo que essa modalidade de ensino traga benefícios de custo e tempo durante a formação profissional pode haver alguns déficit que podem ser sanados para um melhor desempenho desses profissionais. Além de identificar as dificuldades e benefícios gerados por essa modalidade de ensino ele pretende colher resultados qualitativos por meio de entrevista semiestruturada feita a partir de um questionário cujas perguntas nos levaram a compreender as reais motivações da escolha desses profissionais por esse modelo educacional para sua formação. Foram entrevistados 3 (três) docentes que realizaram especializações nessa modalidade de ensino em áreas diferentes,que atuam no município trazendo também a importância desses ambientes educacionaispara estes profissionais, a pesquisa foi realizada em 6 (seis) etapas que colaboraram para o êxito da pesquisa onde devido ser feita em forma de entrevista se obtiveram dadosalém de importantes sobre quais áreas foram escolhidas e o porquê desta escolha,foi possível saber também de que forma as escolas lidam com a formação desses professores.

\footnotetext{
${ }^{1}$ Curso de Licenciatura em Computação da Instituto Federal de educação, ciências e tecnologia do TocantinsCampus Araguatins - IFTO, kellyluanasousasilva@gmail.com

${ }^{2}$ Curso de Licenciatura em Computação da Instituto Federal de educação, ciências e tecnologia do TocantinsCampus Araguatins - IFTO, tiago12399@hotmail.com

${ }^{3}$ Mestre em educação, Instituto Federal de educação, ciências e tecnologia do Tocantins-Campus Araguatins IFTO, ramasio.ml@gmail.com
} 
Palavras-Chave:EaD, Professores, Formação para docentes.

\title{
Resumen
}

La formación y especialización a distancia de los profesores se ha vuelto cada vez más frecuente y en la red pública de todo el país no es diferente, ya que se llevó a cabouna investigación en las instituciones escuelas de enseñanza municipales en la ciudad de Araguatins - Para nalyze cómo la educación a distancia ha influido en la formación académica de los maestros en estas escuelas, debido a este crecimiento, una evaluación del desempeño y dificultades encontradas por estos profesionales durante su formación y prácticas, y requiere una mayor atención del gobierno y las escuelas, porque incluso si esta modalidad de educación aporta beneficios de costo y tiempo durante la capacitación puede haber algún déficit que puede ser sanados para un mejor rendimiento de estos profesionales. Además de identificar las dificultades y beneficios generados por esta modalidad de enseñanza pretende obtener resultados cualitativos a través de entrevistas semiestructuradas realizadas a partir de un cuestionario cuyas preguntas nos llevaron a entender la motivaciones de la elección de estos profesionales por este modelo educativo para su formación. Treinta (tres) profesores que realizaron especializaciones en esta modalidad de enseñanza en diferentes áreas fueron entrevistados, que trabajan en el municipio, aportando también la importancia de estos entornos educativos estos profesionales, la investigación se llevó a cabo en 6 (seis) etapas que colaboraron para el éxito de la investigación donde debido a ser hecho en forma de entrevista, los datos se obtuvieron además de importante sobre qué áreas se eligieron y por quéestaelección, también fue posible saber cómo las escuelas tratan con la formación deestos maestros.

Palabras Clave:EaD, profesorado, formación de profesores.

\begin{abstract}
Teacher distance training and specialization has become increasingly frequent and in the public network across the country is no different, as a research was conductedin the institutions municipal teaching schools in the city of Araguatins - TO to nalyze how distance education has influenced the academic training of teachers in these schools, due to this growth, a performance assessment and difficulties encountered by these professionals during their training andpractices, and requires greater attention from the government and schools, because even if this modality of education brings cost and time benefits during training there may be some deficit that can be sanados for better performance of these professionals. In addition to identifying the difficulties and benefits generated by this modality of teaching he intends to collect qualitative results through semi-structured interviews made from a questionnaire whose questions led us to understand the motivations of the choice of these professionals by this educational model for their training. Thirty (three) teachers who
\end{abstract}


performed specializations in this modality of teaching in different areas were interviewed, who work in the municipality, also bringing the importance of these educational environments to these professionals, the research was conducted in 6 (six) stages that collaborated for the success of the research where due to be done in the form of an interview, data were obtained in addition to important about which areas were chosen and whythischoice, it was also possible to know how schools deal with the training ofthese teachers.

Keywords:EaD, teachers, teacher training.

\section{Introdução}

A educação é um direito de todos como é assegurado no Art. 205 da constituição que diz "A educação, direito de todos e dever do Estado e da família, será promovida e incentivada com a colaboração da sociedade, visando ao pleno desenvolvimento da pessoa, seu preparo para o exercício da cidadania e sua qualificação para o trabalho." Por isso foi criado modalidades de ensinos para assegurar a todas as pessoas esse direito a educação, essas modalidades são utilizadas como auxílio na aprendizagem e formação da comunidade que não pode ter acesso à educação como assegura a Lei de diretrizes e bases da educação nacional no art. 80 que diz:

\footnotetext{
O Poder Público incentivará o desenvolvimento e a veiculação de programas de ensino a distância, em todos os níveis e modalidades de ensino, e de educação continuada. (Regulamento) (Regulamento)

$\S \mathbf{1}^{\mathbf{0}}$ A educação a distância, organizada com abertura e regime especiais, será oferecida por instituições especificamente credenciadas pela União.

$\S \mathbf{2}^{\circ}$ A União regulamentará os requisitos para a realização de exames e registro de diploma relativos a cursos de educação a distância.

$\S 3^{\mathbf{o}}$ As normas para produção, controle e avaliação de programas de educação a distância e a autorização para sua implementação, caberão aos respectivos sistemas de ensino, podendo haver cooperação e integração entre os diferentes sistemas. (Regulamento).
}

$\mathrm{Na} \mathrm{EaD}$ é necessário que tenha profissionais especializados na área de atendimento educacional que está sendo oferecido o curso, e que estes saibam utilizar as ferramentas tecnológicas para que possam saber lidar com as necessidades tantoeducacionais dos alunos como de utilização das tecnologias da informação e comunicação (TIC's) que serão usadas, pois elas trazem uma visão diferenteem relação ao ensino e oferecem oportunidades de formação para muitos como afirma(SILVA; BASTOS, 2017, pag.743) “A EAD, desde suas 
origens, apresenta-se como uma modalidade de educação que possibilita novas oportunidades de acesso à escolarização, formação profissional e continuada.”.

Este artigo tem como principal aspecto apresentar quais são as consequências da utilização da EaD na formação acadêmica dos professores como metodologia de auxílio na construção de novos conhecimentos e nas dificuldades de aprendizagem desses profissionais.

Propõe-se apresentar a importância da aprendizagem dos professores através do gerenciamento e da criação de situações didáticas que foram enfrentadas por eles durante sua formação através de questionários de forma que o potencial deles seja valorizado possibilitando a flexibilidade e a interdisciplinaridadedentro da modalidade de ensino escolhida conforme (KENSKI, 2009, p. 48)“(...) oportunidade de conhecimentos e de reflexão sobre sua identidade pessoal, como profissional docente, seus estilos e seus anseios" .

Procura compreender as principais consequências geradas nesses profissionais durante e após a sua formação ou especialização acadêmica na modalidade de ensino em EaD, considerando novas formações por parte deles nesta modalidade.

Dessa forma, a educação a distância pode ser utilizada por esses profissionais como uma ferramenta facilitadora durante a formação, podendo ser aprimorada para que estes docentes apliquem algumas das metodologias e TDIC's durante as aulas trazendo assim uma nova visão sobre a educação e avaliação das dificuldades encontradas, avaliando o impacto da formação em EaD em suas formações.

\section{Fundamentação Teórica}

A inclusão da educação a distância no meio educacional vem se tornando cada vez mais frequente tanto em escolas públicas como privadas, com a formação de pessoas que não podem ter acesso presencial a escolas públicas ou privadas, levando até elas o ensino aprendizagem por meio das TICs como afirma ALONSO; SILVA.:

\footnotetext{
"Valendo-se disso, das emergentes possibilidades que as TIC engendram aos processos formativos, presencia-se, nos últimos anos, vertiginosa expansão da oferta de formação por meio da $\mathrm{EaD}$, com uso mais intenso dos ambientes virtuais de aprendizagem (AVA) e, mais recentemente, das redes sociais (RS) implicadas em processos de aprendizagem ou de constituição de espaços de práticas culturais da cultura digital no espaço escolar” (ALONSO; SILVA, 2018, pag. 501.).
} 
Existem inúmeras opiniões sobre a utilização das TDIC dentro das salas de aulas por educadores, trazendo preocupação de que forma estas tecnologias seriam trabalhadas nas escolas e quais profissionais deveriam manuseá-las.

\begin{abstract}
Há os que pensam que o educador precisa ser incentivado a usar o computador com seus alunos. Há os que pensam que é preciso um técnico em informática para ensinar os alunos a operarem o computador. No entanto, é necessário que o próprio professor, com formação na área que está sendo ministrada, tenha familiaridade com a informática (MATTOS; TUTTMAN; GUIMARÃES, 2008, pag. 102).
\end{abstract}

Essa modalidade de ensino está crescendo não somente no meio da comunidade mas desfavorecida financeiramente, com menos acesso à educação ou sem formação superior mas também em meio a profissionais já qualificados e com formação superior que procuram estar em constante qualificação e aprendizado, que é o caso de alguns professores que tem essa necessidade e que devem também ter uma flexibilidade de horário, optam pela formação em EaDde acordo com SANTOS.:

Educação à Distância democratiza o acesso à Educação, atendendo a alunos dispersos geograficamente e residentes em locais onde não haja instituições convencionais de ensino. Exigindo menor quantidade de recursos financeiros. Propicia uma aprendizagem autônoma e ligada à experiência dos alunos, que não precisam se afastar do seu local de trabalho. Promove um ensino inovador e de qualidade, garantindo o acompanhamento dos tutores, para tirar dúvidas, incentivar e avaliar os alunos. Incentiva a Educação Permanente, permitindo a atualização e o aperfeiçoamento profissional daqueles que querem aprender mais. Permite que o aluno seja realmente ativo, responsável pela sua aprendizagem e, principalmente, aprenda a aprender. (SANTOS,2006, pag.4.)

Com a popularização da $\mathrm{EaD}$ o governo viu a precisão de projetos de formação nesse ambiente com a utilização da modalidade $\mathrm{EaD}$ para isso foram criados projetos educacionais a distância voltado exclusivamente para esses profissionais como o "Plano Nacional de Formação de Professores da Educação Básica (PARFOR), o qual se constitui em um programa emergencial cujo objetivo é oferecer formação em ensino superior para professores que atuam na educação básica na rede pública.”( BRITO; GUILHERME, 2017, pag.117.) . 
Por essa razão deve-se criar políticas, mas justas para a adaptação e inclusão dessas pessoas dentro do âmbito escolar de EaD que possa facilitar o acesso a e aprendizagem desses professores para que a haja uma transmissão de conhecimento.

\begin{abstract}
A Educação a Distância (EaD) se refere a uma modalidade de educação, ou seja, a um processo de transmissão, construção e reconstrução do conhecimento e da formação de cidadãos conscientes de seu papel em nossa sociedade, comprometidos em seus ambientes sociais e em suas atividades profissionais (GIANNELLA; STRUCHINER; RICCIARD, 2004 apud DURLI; ARCHER; ESPÍNDOLA; BORGATTO, 2018, pag. 352.).
\end{abstract}

A EaD funciona de duas formas primeira: o aluno assiste aulas durante o horário que é mais conveniente a ele com o auxílio de ferramentas de tecnologia da informação e da comunicação que são utilizados; computador, internet, apostila online, vídeo aulas e outros aplicam metodologias para facilitar a apreensão dos conteúdos.

\footnotetext{
O professor do curso organiza a informação de acordo com uma sequência que ele entende ser a mais adequada e essa informação é enviada ao aluno, utilizando-se dos meios tecnológicos como já aconteceu com o material impresso, o rádio e a televisão. No entanto, o computador também pode ser utilizado para "entregar" a informação ao aluno, usando, por exemplo, os recursos da Internet. Nesse caso, o professor armazena as lições em um determinado arquivo, em um servidor e os alunos, via Internet, podem ter acesso a esse servidor, ao arquivo e, consequentemente, às lições. (VALENTE, 2018, pag. 2).
}

A segunda forma seria uma maneira semipresencial onde o aluno tem uma carga horária de atividades e aulas online ou com uso das TICs e o restante desses horários seria preenchido com aulas presenciais onde os professores das salas regulares utilizam novas ferramentas de ensino para promover uma melhor interação entre o aluno e seus colegas. Há vários tipos de metodologias que podem e são aplicadas na modalidade de $\mathrm{EaD}$ para melhorar o aprendizado destes alunos conforme diz NOVELLO; LAURINO.:

\footnotetext{
Aliás, quanto à complexidade de constituição desse processo, cabe ainda salientar que uma das questões observadas na EAD está no fato de que ela é formada por coletivos de profissionais, com estratégias e instrumentos de trabalho singulares que trazem marcas e visões decorrentes de seus processos formativos e de suas
} 
experiências no ensino presencial. Assim, investir nas relações interpessoais e na constituição de grupos de trabalho voltados para a promoção da aprendizagem é um dos desafios latentes, uma vez que, nessa modalidade, o trabalho coletivo, que conjugue os profissionais de diferentes habilidades e formação, emerge no ato de fazer a EAD.

(NOVELLO; LAURINO, 2012, pag.2.).

Dessa forma podemos observar o quanto a educação a distância é algo que supera a visão de que é uma coisa impessoal que não ultrapassa os limites tecnológicos, onde o indivíduo lida somente com uma máquina sem um contato humano pois como podemos perceber existem educadores com metodologias para formar outros educadores e indivíduos da melhor forma possível.

Não se pode também deixar de levar em consideração o fato de que dependendo do sujeito isso pode mudar e se mostrar um método ineficaz segundo GONÇALVES:

\footnotetext{
"Há situações em que a presencialidade na avaliação é condição de aperfeiçoamento da aprendizagem - aquelas que envolvem algumas habilidades motora complexa, por exemplo. Nestas situações, a não previsão de avaliação ou de avaliação presenciais poderia ser tida como irresponsável; pois, se é imprescindível para a aprendizagem, torna-se um direito do aluno a ser respeitado" (Gonçalves, op.cit. 07).
}

Assim deve se levar em consideração qual a melhor alternativa para o indivíduoseguir, mas nunca tendo em vista a desistência. Os métodos que o professor utiliza pode servir como apaziguador dessas problemáticas para alguns indivíduos.

\section{Metodologia}

$\mathrm{O}$ artigo foi realizado com professores regentes nas escolas de ensino municipais de Araguatins, esses professores foram escolhidos para serem pesquisados pela necessidade de entender as dificuldades dos professores em usar a modalidade de ensino EaD durante suas formações acadêmicas. A pesquisa de campo possibilitará conhecer os sujeitos da pesquisa para entender suas reais opiniões quanto a inclusão deste tipo de formação no meio desses profissionais e sobre a importância da construção de novos conceitos aos professores, através da $\mathrm{EaD}$ e das TIC's. 
Este estudo fundamenta-se em revisão bibliográfica oriundos da internet, uma entrevista e observações, de característica qualitativa, almejando resultados que representem alguma das motivações desses profissionais para a escolha desse tipo de modalidade e a qualidade de ensino-aprendizagem obtidas durante esse processo.

Figura 1: Fluxograma das etapas do desenvolvimento da pesquisa

\section{Etapa 1: Estudo de bibliografias}
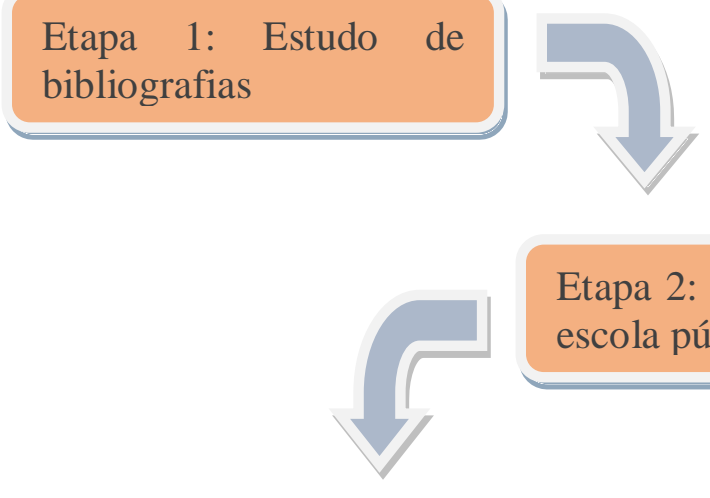

Etapa 2: Seleção de uma escola pública

\section{Etapa 3: Visita à escola.}

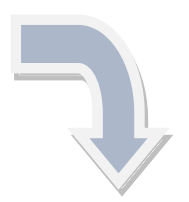

\section{Etapa 4: Entrevista com} os professores

Etapa 5: Análise dos dados.

Etapa 6: Escrita dos dados analisados.

Fonte: Própria (2019). 
No fluxograma acima pode notar 6 etapas fundamentais para a conclusão desde trabalho que são seguintes:

1. Etapa: Estudo de bibliografias: as escolhas das bibliografias foram de grande importância pois a parte delas podemos ter um embasamento para a pesquisa, foram escolhidas tanto pelos acadêmicos como pelo orientador.

2. Etapa: Seleção de uma escola pública: A escola foi uma etapa bem relevante pois a cidade não possui muitas escolas municipais porem o principal motivo para a escolha eram os profissionais, pois a um certo tabu relacionado aestagnação na formação desses docentes.

3. Etapa: Visita à escola: A visita a escola foi realizada principalmente para a averiguação de profissionais que tinham a formação específica para a pesquisa e autorização para mesma.

4. Etapa: Entrevista com os professores: Os professores selecionados preenchiam os seguintes requisitos: Trabalhavam na rede pública, atuavam em sala de aula, tinha uma segunda ou primeira formação na modalidade EaD.

5. Etapa: Análise dos dados: Os dados obtidos por meio de entrevista foram debatidos entre os acadêmicos e orientador, averiguando o que seria pertinente a pesquisa.

6. Etapa: Escrita dos dados analisados: Após analisar os dados se deu continuidade a escrita dos trabalhos focando principalmente na avaliação e montagem dos dados obtidos.

\section{Estudo e seleção de bibliografias}

Para esse estudo foram consultadas quinze (15) referências bibliográficas, sendo livros e artigos pertencentes a revistas de qualis $\mathrm{B}$, porém, apenas dez (10) foram usados em todo trabalho, justificando-se principalmente pela importância e influência da $\mathrm{EaD}$ na formação acadêmica desses profissionais. Para isso, selecionou-se os mais próximos da realidade escolar do município de Araguatins.

\section{A entrevista}


A segunda parte da pesquisa consistiu na entrevista com Três (3) funcionárias A, B e C (nomes fictícios para esse trabalho) das escolas municipais sendo todas do Maria de Lourdes, devido a não se encontrar docentes formados (e o que tinha preferiu não responder a entrevista) em EaD no Nair Duarte. Aplicou-se algunsquestionários, onde uma das vias foi entregue ao entrevistado, este consistia em perguntas abertas que foram feitas aos três durante a entrevista registradas em um bloco de notas, e gravação em áudio com a permissão aprovada pela escola e a entrevistada.

\section{Entrevistados}

Dos entrevistados duas (2) eram do sexo feminino (A e B) com as idades de 39 e 44 anos e um (1) do sexo masculino (C) com a idade de 38 anos, suas respectivas formações eram:

- A - Formação inicial Pedagogia, cursando em Ead especialização em Atendimento Educacional Especializado;

- B - Formação inicial educação, formada em Ead especialização em Atendimento Educacional Especializado;

- Formação inicial Pedagogia, cursando em Ead especialização em Matemática.

\section{Resultados e Discussão}

As teorias estudadas e apresentadas no decorrer deste artigo assegura que os dados obtidos partiram do pressuposto constado em artigos, e revistas, fontes de grande valia, que serviram para esclarecer algumas metodologias e benefícios da educação a distância, e tirar possíveis dúvidas referentes às mesmas, mesmo sendo uma forma de fácil acesso à educação, na maioria das vezes não é usada por um grande público, devido à falta de recursos direcionados a adaptação das escolas para a recepção desses alunos, ou medo da perca de dados ou desconhecimento das tecnologias.

Um fator que chamou a atenção e que foi comentado por um dos pesquisados foi que a escola oferece aos docentes a oportunidade de realizar especializações em Ead com aulas presenciais 1 (uma) vez ao mês (não se sabe se todos os educadores tem essa proposta)porém 
ainda se encontra uma baixa quantidade de professores formados dentro deste modelo de ensino como vemos no gráfico abaixo:

Figura 2:Tipo de formação dos professores nas escolas pesquisadas.

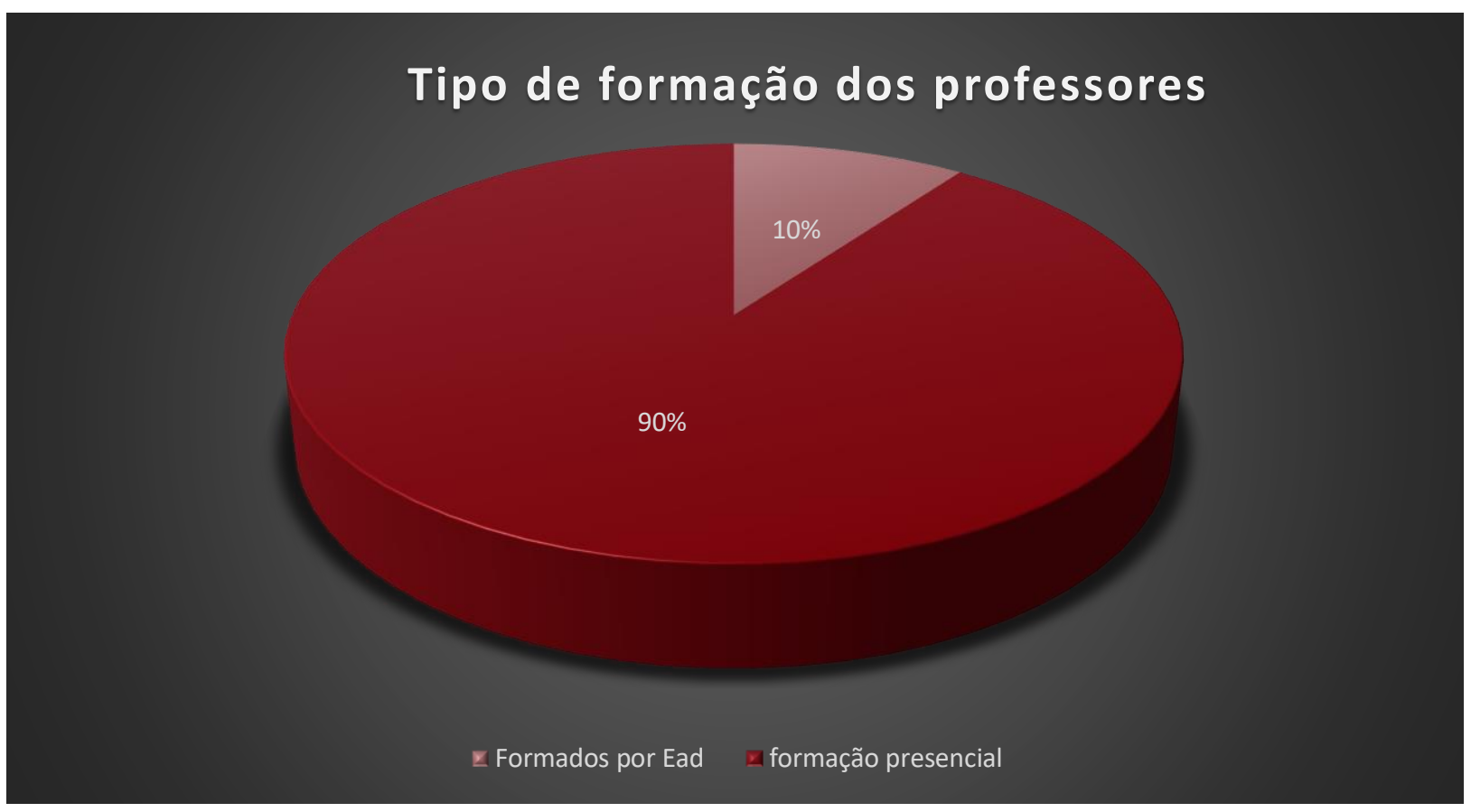

Fonte: Própria (2019)

Conseguimos observar que mesmo com chances de se especializar alguns não o fazem por falta de interesse, tempo, dinheiro ou por diferentes motivações onde não se foi pesquisado. No entanto isso mostra como a educação a distância está bem presente no meio educacional.

Durante a entrevista foram identificados algumas motivações e problemas em comuns entre os entrevistados A, B e C que interferiam tanto para a escolha do curso em EaD como no percurso até a formação destes, desse modo, a tabela abaixo representa tais dificuldades.:

Figura 3: Tabela de dados sobre as motivações dos professores para a formação em Ead.

\begin{tabular}{|l|}
\hline \multicolumn{1}{|c|}{ Motivações } \\
\hline Melhoria das suas metodologias em sala. \\
\hline Curso não ofertado na cidade. \\
\hline
\end{tabular}


Disponibilidade de tempo.

Especialização para lidar com a demanda de alunos na instituição.

Necessidade de uma formação para a maior gratificação monetária.

Fonte: Própria (2019)

Figura 4: Tabela de dados sobre as problemáticas citadas pelos professores para não formação em Ead.

\begin{tabular}{|l|}
\hline \multicolumn{1}{|c|}{ Problemáticas } \\
\hline $\begin{array}{l}\text { Não receber uma remuneração adequada por sua formação, pois muitos passam } \\
\text { bastante tempo na lista a espera de progressão; }\end{array}$ \\
\hline Medo de ter os dados pessoais utilizados de maneira indevida. \\
\hline Não saberem lidar com as ferramentas tecnológicas utilizadas durante o processo. \\
\hline Plataformas má organizada (Atividades, trabalhos e conteúdo). \\
\hline Receio de que não consiga aproveitar o conhecimento necessário do curso por não \\
absorverem devido conhecimento. \\
\hline Contratar terceiro para realizar as atividades em seu lugar. \\
\hline Falta de contato "humano". \\
\hline
\end{tabular}

Fonte: Própria (2019)

Pode-se notar que o maior problema que os entrevistados encontraram no decorrer do curso eram as plataformas desorganizadas onde por já terem dificuldades com as ferramentas tecnológicas ainda não sabiam lidar com conteúdo e atividades embaralhadas, com isso optavam por procurar alguém com maior conhecimento nessa área para lhes auxiliar durante o uso da plataforma.

Fazer a descrição dos dados obtidos e principais resultados, fazer relação entre os dados obtidos e as hipóteses de pesquisa, apresentar dados inesperados que apareceram e que acha interessante destacar. Interpretar os resultados e discutir, tendo como base a fundamentação teórica. 


\section{Conclusões}

As discursões e resultados apontados pelos pesquisadores e pelos artigos e livro pesquisados contrastam a realidade de formação para professores do município de Araguatins, local de estudo desse trabalho, e ainda mais de foco na implantação e divulgação dos curso de EaD para esses profissionais, e enfatiza a importância de se haver investimentos na criação de espaços e recursos para essa modalidade de educação, cuja atenda e proporcione, sobretudo, acesso à educação a qualquer indivíduo, independente da distância.

Além disso, é necessário que o governo faça investimentos na área da tecnologia para que estes profissionais possam saber utilizar essas ferramentas adequadamente, dessa maneira não haverá a necessidade de procurar outras pessoas para acessar auxiliá-los durante as atividades correndo assim um menor risco de ocorrer fraudes nas atividades.

As plataformas de ensino que ofertam cursos a distância também devem procurar melhor suas plataformas de modo que facilitem o manuseio de seus recursos e atividades procurando atender e satisfazer todas necessidades do seu público, como já foi dito essas pessoas procuram uma maneira, mais simples de conseguir uma formação que não é ofertada dentro do município.

Contudo podemos observar que a um grande défice na modalidade em $\mathrm{EaD}$ no município mesmo que haja demanda de pessoas a empecilhos que as impedem de usufruir disso devido ao medo, não saber utilizar as ferramentas tecnológicas, plataformas desorganizadas ou simplesmente o desconhecimento.

Algo bem interessante chamou a atenção durante a pesquisa a entrevistada B (primeira ser entrevistada) disse que as vezes pedia a filha mais velha que sabia mexer com tecnologia para fazer alguma atividade para ela, porém com ela sempre por perto mas que sabia que alguns professores pagavam para que outras pessoas fizessem atividades e provas em seus lugares, então nas entrevistas seguintes perguntei aos dois últimos entrevistados se pagaram para terceiro realizar os exercícios em seu lugar e estes negaram.

Então devemos ter uma preocupação em quem realmente está realizando as atividades e provas por isso é tão importante que aja além das aulas presenciais atividades que exijam vídeo conferencia, chats e fóruns onde o professor possa manter um maior contato com os alunos e também um incentivo governamental a esses docentes para trabalhar com tecnologias audiovisuais onde trabalhe com eles alternativas diferentes que os incentive a crescer 
intelectualmente os tornando mais receptíveis a mudanças, esta foi uma das principais desmotivações apontadas pelos 3 (três) entrevistados, a falta de conhecimento tecnológico pois fora celulares, redes sociais, projetor (Multimidia) e o programa escolar de diários escolares eles não tinham nenhum outro tipo de contato mais aprofundado com a tecnologia.

Este trabalho está aberto a servir como eixo de pesquisa a novos estudos, aprofundamento teórico e de aplicação metodológica para futuros pesquisadores pois é um tema vasto e inovador onde se a muito que ser analisado.

\section{Referências}

ALVES, Denise. et al. Sala de Recursos Multifuncionais: Espaços para Atendimento Educacional Especializado. Brasília: Ministério da Educação, Secretaria de Educação Especial, 2006.

ALONSO Katia Morosov, SILVA Danilo Garcia da. A EDUCAÇÃO A DISTÂNCIA E A FORMAÇÃO ON-LINE: O CENÁRIO DAS PESQUISAS, METODOLOGIAS E TENDÊNCIAS. Revista Educ. Soc. vol.39 no.143 Campinas Apr. /June 2018.

KENSKI, V. M. Tecnologias e Ensino presencial e a distância. 7. ed. Campinas: Papirus, 2009. p. 157.

SENADO FEDERAL. Atividade Legislativa, Brasília, mar. 2017.Disponível em <https://www.senado.leg.br/atividade/const/con1988/CON1988_05.10.1988/art_205_.asp>. Acesso em 13 de dezembro de 2018.

SENADO FEDERAL. LDB: Lei de diretrizes e bases da educação nacional, Brasília, jun. 2018. Disponível em <https://www2.senado.leg.br/bdsf/handle/id/544283>. Acesso em: 14 de Dezembro de 2018.

SANTOS João Francisco Severo, Avaliação no Ensino a Distância na EAD. Revista Iberoamericana de Educación (Bauru) 2006. Acessado em 22 Dezembro de 2018 Disponívelem: $<$ https://www.researchgate.net/publication/28107759_Avaliacao_no_Ensino_a _Distancia>ISSN: 1681-5653

Teixeira Bruno Silva, Ana Paula, Brasil Nóbrega Bastos, Heloisa Flora, Uma proposta metodológica para o estágio curricular supervisionado na EAD: articulações entre CEK e Grupo Cooperativo. Ciência \& Educação (Bauru) 2017, v.23. Acessado em 22 dezembro de 2018 Disponível em: $\leq$ http://www.redalyc.org/articulo.oa?id=251053225013>ISSN 15167313

VALENTE, José. Diferentes abordagens da educação a distância por computador e via internet. Repositório aberto: Universidade Aberta, 2014. 
GONÇALVES, C. T. F. (1996): “Quem tem medo do ensino a distância?”, in Revista Educação a Distância, n. ${ }^{\circ}$ 7-8, INED/IBASE.

NOVELLO Tanise Paula, Debora Pereira LAURINO, AEducação a distância: seus cenários e autores Revista Iberoamericana de Educación 2012, no 58. Acessado em 22 Dezembro de 2018 Disponível em:< falta a url>ISSN: 1681-5653.

Mattos, Joy Costa. Prática de ensino 2. v. único / Joy Costa Mattos; MalvinaTaniaTuttman; Nilci da Silva Guimarães. - Rio de Janeiro: Fundação CECIERJ, 2008. 